\title{
Orchestrating Innovative SME Networks. The Case of "HealthInnovation"
}

\author{
Anne Haugen Gausdal • Etty Ragnhild Nilsen
}

Received: 10 January 2011 / Accepted: 30 September 2011 /

Published online: 18 November 2011

(C) Springer Science+Business Media, LLC 2011

\begin{abstract}
This paper develops a framework for the orchestrating process of networks of independent small- and medium-size enterprises (SMEs). The existing literature on network orchestration is developed for large networks with a dominant hub firm managing up to 500 members. We argue that SME networks need a somewhat different approach to orchestration. We find the literature on communities of practice appropriate to that aim. The empirical base is a longitudinal study of the development of HealthInnovation, a regional network of independent SMEs. Originally, the network emerged as "a good idea" in the regional university, but it soon proved to be poorly rooted in the regional industry and in the public sector. Nonetheless, as a result of intensive orchestration, it has become a dynamic and innovative network with several important results: two new firms, several new research and innovation projects, and the development of a new subject at the university. In this study, we ask: What are the processes of successfully orchestrating innovative SME networks? We maintain that in order to successfully orchestrate such networks, the orchestration process consists of managing knowledge mobility, managing innovation appropriability, managing network stability, and managing network health. Managing network health is our specific contribution.
\end{abstract}

Keywords Network orchestration · Network leadership $\cdot$ Network failure $\cdot$ SME networks $\cdot$ Communities of practice

\section{Introduction}

In the learning economy and at times of increasing globalization, both geographical proximity and regional cooperation paradoxically appear to be of increased importance to firms' competitiveness $[22,26]$. Such cooperation is often deployed

\footnotetext{
A. H. Gausdal $(\bowtie) \cdot$ E. R. Nilsen

Buskerud University College, P.O.Box 235, 3603 Kongsberg, Norway

e-mail: ang@hive.no 
in the form of networks. Firms generally enter networks to increase innovation and competitiveness, but this is no guarantee for success [19]. It appears that orchestration, or management processes, constitutes a critical factor for network success $[6,31]$. This paper aims at creating a new framework for the orchestration process of developing networks of small- and medium-sized enterprises (SMEs). It does this by including elements from the literature of communities of practice (CoP) $[2,14,30]$. There is a lack of research on network orchestration [24], and, as Batterink et al. [1] state: "Further research into the multifaceted orchestration process in innovation networks of SMEs remains essential if we want to fully understand how innovation networks function and why innovation networks succeed or fail." Hoang and Antoncic [18] ask for more longitudinal, qualitative, process- and outcome-oriented research on networks; moreover, Freeman [13] claims that "longitudinal case studies on the evolution of networks could be particularly valuable." The research question is: What are the processes of successfully orchestrating innovative SME networks?

To answer this question, the paper discusses theoretical insights and illustrates a longitudinal process-oriented case study of the development of an experimental project. The experimental project is a regional innovative SME network-HealthInnovation, which was studied from 2006 to 2010, with a qualitative approach including some elements of action research. The network combines two business sectors, health care and technology, and this combination is new to the region. In 2008, the network was found to be in a bad condition and very close to failure. Making this diagnosis and devising a strategy for recovery constitute important empirical findings. From being simply a good idea launched by the regional university, but without being rooted in the regional industry or in the public sector, it has become a dynamic network with active firms and an active public sector.

Network orchestration was originally defined by Dhanaraj and Pharkhe ([6]: 659) as the set of deliberate, purposeful actions undertaken by a hub firm to create value ("expand the pie") and extract value ("gain a larger slice of the pie") from the network. Their framework for network orchestration is developed for large "hub firm networks" with a dominant firm managing up to more than 500 alliances simultaneously. Such hub firm networks are typically common in supplier networks, e.g., in large industries like the car industry [9]. However, many innovative networks-like the one under study - lack the dominant hub firm and consist of a small number-often 10-30 — of independent firms, typically SMEs. Since the definition of network orchestration holds the word hub firm, and the role of the hub firm is so central in it, there is a need for a broader definition that also applies to SME networks. We therefore suggest defining network orchestration as the set of deliberate, purposeful actions to create and extract value from the network.

Batterink et al. [1] argue that Dhanaraj and Pharkhe's [6] framework also fits networks of independent SMEs. We agree with Batterink et al. [1] that the framework fits, but argue that the SME networks need a somewhat different approach to orchestration. This is mainly because they have different structures, different size, and - due to scarce resources - SMEs must be selective about what to participate in. In a network with a dominant hub firm, the other firms are generally hub firm suppliers and therefore dependent on participating in the network in order to continue their business with the hub firm. For these networks, market access is a 
built-in business contribution for their members, with power concentrated within the hub firm. Networks of independent SMEs lack a hub firm in the value-chain sense, and will therefore have a different power structure. In an SME network, power is more evenly distributed among its members. The glue that keeps the firms together must be found elsewhere than in the regular customer-supplier transactions - as must the means of orchestration. We therefore think Dhanaraj and Pharkhe [6] framework lacks a process to keep the glue together, as well as a strategy for the recovery of failing networks. Such a process is what we develop in this paper, denoting it "managing network health." We define managing network health as the process of evaluating the network's contribution to members, and the construction of a strategy for the recovery of failing networks.

\section{Network Orchestration}

Dhanaraj and Pharkhe [6] argue that network orchestration consists of three processes: managing knowledge mobility, managing innovation appropriability, and managing network stability. Managing knowledge mobility is at the core of an innovative network, since knowledge is the key resource, while knowledge sharing and knowledge creation are the key processes. Managing knowledge mobility involves sharing, acquiring, and deploying knowledge. Some dimensions of knowledge are inherently sticky [28], which means that knowledge will stay within organizational boundaries unless mobility is managed. Managing knowledge mobility includes facilitating common meeting places for learning, and must overcome obstacles like tacit knowledge, epistemic barriers, lack of trust [3], diverging vocabulary, and so on. Such processes are not only stressed in the literature of network orchestration, but also in the network literature in general. Uzzi [29], for instance, states that social interactions, trust, rich information sharing, and joint problem solving, rather than formal contracts, are vital success factors for a network.

Managing innovation appropriability is highly dependent on managing knowledge mobility. Appropriability is an environmental characteristic property that governs an innovator's ability to capture the profits generated by an innovation [6], and this is the ability to recognize innovative ideas and commercialize these. Such development of viable projects is critical in innovative networks.

Managing network stability is vital due to the nature of SME networks: they are voluntarily formed, they can be labeled "loosely coupled" [23] and they are fragile. On the other hand, network stability constitutes a paradox in that innovation and creativity presupposes dynamism and loosely coupling in networks, and-at the same time-instability can impede innovation. Dhanaraj and Pharkhe [6] do not define network stability as such; rather, they operationalize the threats to network stability as isolation, migration, cliques, and attrition. As orchestrator, the hub firm can meet these threats by increasing "the network's dynamic stability in several ways: by enhancing reputation, by lengthening the shadow of the future, and by building multiplexity" ([6]: 664). A hub firm can, according to Dhanaraj and Pharkhe [6], increase stability by developing its own strength through its reputation and leadership in the market. This is due to members seeking the legitimacy given by links to market leaders. The shadows of the future can, according to Dhanaraj and 
Pharkhe [6], be lengthened by thickening the nexus between current moves and future consequences. This motivates the members to remain in the network with the prospect of future gains. To increase the multiplexity, the hub firm can undertake additional joint projects with network members and thereby expand the scope of the relationships [6]. These remedies are orchestrated by the hub firm and will result in greater dependency and loyalty towards the hub firm - which in turn will decrease isolation. Network stability hinders unstable linkages among network members and contributes to keep the firms collaborating. In a hub firm network the collaboration between the members and the hub firm is by nature the most important one. In a SME network, however, collaboration between all members is equally important, at least at the outset. Furthermore, size does matter. We argue that because hub firm networks and SME networks have different structure, the process of managing their stability will differ.

As the above discussion reveals, managing network stability alone does not create adequate glue in SME networks, so we have searched elsewhere for supplement. Saxenian [26] and Keeble and Wilkinson [21] acknowledged the influence of communities in facilitating regional innovative networks. The existing literature on communities of practice $(\mathrm{CoP})$ is vast and shows that the most critical factor in a community is the vitality of its leadership [31]. It can, however, be argued that the community of practice (CoP) framework was outlined for intra-organizational life and without networks in mind.

In communities of practice, social relations are created around work, or practice, since "CoPs limit itself to communities where practice is coordinated or at least is shared" ([7]: 82). Such relations imply that the joint enterprise exceeds the goal of the task itself; it is also the collective process of performing the task and creating a mutual accountability along the way. Practice is what links the individuals that form the community, and, through practice, identities are formed and knowledge is developed. In a network context, practice as in work in itself is not necessarily the common denominator, and the question arises of whether the interaction in the network can be seen as shared practice. The members of Healtinnovation currently share knowledge, but they do not share work. However, the concept of networks of practice does not demand a coordinated practice [8], since a network of practice "designates the collective of all practitioners of a particular practice" ([7]: 78). The relations among networks of practice members are significantly more loose than those within CoP. Networks of practice members do not necessarily work together, but they are engaged in the same or very similar practice, and share a great deal of insight and implicit understanding [2]. This does not, however, necessarily happen through collaborative, coordinated practice and direct communication as in a CoP. The network under study is a collective of practitioners. However, as we shall see later, the network under study presents greater similarities with a community of practice than with a network of practice. This is due to (1) the shared practice that develops in the workshops and projects, and other types of interaction aimed at becoming also a coordinated practice, and (2) the composition of the members of the network, which is not marked by shared understanding and insights, but rather by complementary insights in to a shared project and interest in a new market. Because of its regional nature, the network can therefore be categorized as a regional community of practice [14].

We argue, on a par with several others (e.g., $[2,14])$, that the processes of learning and the collective reflection needed for innovation and knowledge creation-which are the basis for communities of practice - also prevail in a network context. The obstacles 
for the network orchestration take on a different form, and the role of the orchestrator appears to be of additional importance. It is therefore profitable to draw on CoP theory within the network context, and in particular on the process of orchestration.

$\mathrm{CoP}$ has proceeded along different trajectories: one is theoretical in orientation, representing the practical turn in social sciences; the other is a more managerial approach, where the framework is developed into a tool kit. In the early development of the concept of CoP, the managerial dimension was almost absent: "They seemed to have no theory of institutions or organizations" [8]. In Wenger's later development, the concept is turned into a managerial tool [31], thus making the $\mathrm{CoP}$ an outcome of management rather than a description of practice [8]. It is this latter version of CoP we take as the basis of this study, by applying part of the cultivation that Wenger et al. [31] suggest. This choice is largely due to the nature of practice in the context of a network. A network rarely experiences the immediate and daily emerging community and meeting places that are underlying assumptions in the original CoP framework, and presupposes to a larger extent facilitation and management of interaction and cooperation. According to the CoP framework, by performing a number of key functions the network orchestrator-or in CoP terms: the community coordinator-helps the community to focus on its domain, maintain its relationships, and develop its practice [31].

The most important factor in a CoP, in the Wenger et al. [31] version, is the vitality of its leadership, and good leaders are typically knowledgeable and passionate about the community's topic. Their primary role is to link people together; therefore, interpersonal skills for networking and the ability to recognize the development needs of individuals are important. Other important qualities are the understanding of group dynamics and having a strategic capacity. CoP managers perform a number of key functions which are outlined in Table 1.

The role of the network manager is described in various shapes in the relevant literature. Dhanaraj and Pharkhe [6] term this function a "network orchestrator", while Batterink et al. [1] in a review of the different forms this role may take, use the term "innovation broker." Wenger et al. [31] denominate this function a "community coordinator." We argue that the processes performed by a community coordinator, or orchestrator, in regional CoPs correspond to several of the processes of network orchestration, and supplement it. These are compared in Table 2.

Table 1 The key functions of CoP leadership ([31]: 80)
The key functions of CoP leadership

Identify important issues in the members' domain

Plan and facilitate community events

Informally link community members, crossing boundaries between organizational units, and brokering knowledge assets

Foster development of community members

Manage the boundaries between the community and the formal organization, such as teams and other organizational units

Help build the practice-including the knowledge base, lessons learned, best practices, tools and methods, and learning events

Assess the health of the community and evaluate its contribution to members and the organization 
Table 2 Comparison of the content of processes in network orchestration and CoP leadership

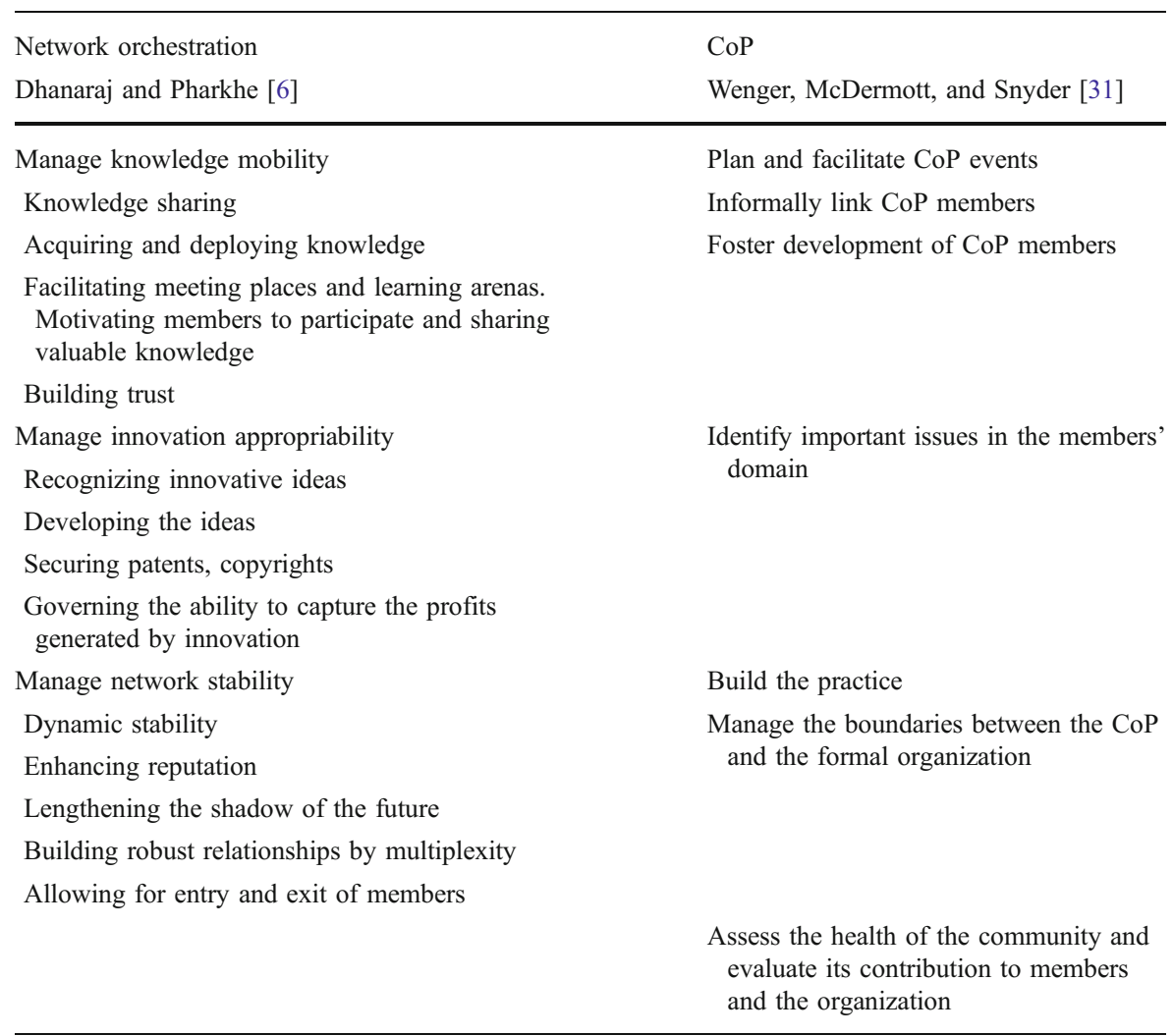

As the comparison shows, the processes of $\mathrm{CoP}$ leadership supplement the literature of network orchestration on assessing the health of the CoP and evaluate its contribution to members. We argue that the existing literature on network orchestration lacks in-depth elaboration on assessing the health of the community, operationalized as: (1) the process of evaluating the network's contribution to members, and (2) the construction of a strategy for the recovery of failing networks. To keep the glue in SME networks working, the networks health condition must be nourished.

\section{Methods}

This study was carried out during the period 2006-2010 using case study methodology, i.e., collecting longitudinal data through interviews, conversations, document studies, participant observation, and elements of action research. A case study is applied here because the issues under study are processes very much linked to their contexts. Moreover, the complexity of the case rules out a cross-sectional questionnaire, in that there are too many "variables" for the number of observations 
made ([17]: 324). The study is a single case study, where the unit of analysis is a network composed by different types of actors, such as private firms, public sector, and academia. During data collection we participated in meetings, seminars, "innovation lunches," and foresight workshops and on one occasion we facilitated the processes. About $90 \mathrm{~h}$ were spent on observation, participation, and conversation with the different actors. Two in-depth interviews and five long conversations were conducted with the orchestrator. Data in the form of field notes, transcribed interviews, and secondary sources have been analyzed using an interpretive and explorative approach, as well as applying existing theoretical frameworks as analytical dimensions. We have tried to strengthen the reliability of the study through researcher triangulation and continuous contact with the orchestrator and the network.

During the interviews, data were collected using a narrative approach. Inspired by Czarniawska [5], we have used a methodology that she calls narrative interviews. Narrative interviews are chronological relations of events that occurred under a specified period of time. This narrative approach has also been used in the presentation of data in this article. The longitudinal data were obtained through the close monitoring of the development processes of the network, by means of participative observation with some elements of action research. In the autumn of 2008 , one of the researchers facilitated a 6-h competency management process for the hospital and the Department of Health Sciences and the Department of Optometry and Visual Science at the regional university. The process was organized as a dialogue process using the Network IGP method [15]. This method is developed by the first author of this paper. IGP is an acronym for individual, group, and plenary reflections; consequently it is a combination of individual and collective reflection. In addition to continuous conversations between the orchestrator and the researchers, in the autumn of 2008, one of the researchers took part in a strategic discussion on the network development with the orchestrator. The last element of action research is our participation in meetings, seminars, "innovation lunches," and foresight workshops as regular participants and researchers. By facilitating interventions, we staged a process combining action and reflection, theory and practice. These are, according to Reason and Bradbury [25], the very features of action research.

In this study, we aim to develop a new framework and, according to Yin [32] and Eisenhardt [10], a case is an appropriate research strategy for theory generation. A single case provides the opportunity for unusual research access and exploration of a specific population [32]. It also affords the possibility to explore and richly describe the existence of a phenomenon [27]. Yin [32] suggests, however, that multiple case studies typically provide a stronger base for theory-building; nevertheless, a single case can be a very powerful example providing a more convincing argument about causal forces than broad empirical research $[12,27]$. In this study, we aim to further develop a framework for network orchestration.

\section{The HealthInnovation Project}

The network development started in 2006, the idea being born within academia, in the regional (state-owned) university. Inspired by the concept of triple helix [11], it started out as an experiment to combine the research environments at the Department 
of Health Sciences and the Department of Optometry and Visual Science at the regional university with the public sector and the regional industry. The idea was that of a cooperation between research and practice, in order to develop a new research area and industry in health and lighting. The focus was on the positive effect of correctly adjusted light for people with different needs, for instance in nursing homes for demented people and in work environments in general. In 2007, the project was granted funds from the Arena program (funding from Innovation Norway) and in 2008 it also received funding from the National Research Council and the county authorities through the VRI funding program (VRI means for regional R\&D and innovation). In 2008, a new full-time project manager, the network orchestrator, was engaged by a regional innovation centre.

\section{Evaluating Its Contribution to Members}

The orchestrator spent a lot of time mapping out and visiting potential firms which could be interested in joining the project, both inside and outside the region. Despite her efforts, very few relevant firms became interested. She endeavored to mobilize both the regional hospital and the municipality; whereas the hospital canceled most of the meetings and demonstrated very little interest, the municipality showed more enthusiasm. Moreover, the regional universities' enthusiasm from the initial phase seemed to have decreased in the two university departments involved.

The orchestrator concluded that the network's contribution to its members was close to zero. It was born and nourished in academia, but their enthusiasm and participation had cooled down. Furthermore, it appeared not to be deeply enough rooted in the regional industry or in the public health sector. Finally, the public funding from the Arena program was threatened to be withdrawn. All in all, the orchestrator evaluated the SME network to be in a state of crisis and close to failure.

The Construction and Implementation of a Strategy for the Recovery of the Failing Network

Instead of devoting effort to continue plodding on the same path, the network orchestrator suggested and implemented radical changes, refocusing the project and reorganizing the board. She guided the project through a dramatic transition, and towards the end of 2008 and early 2009 the board was re-organized and the head of the board was now a manager from an innovative technological firm. As she explained later, "I had to tell the participants that the baby is ugly — and not entitled to life." The original focus on health and lighting was replaced with a broader focus - on health and technology — and the project was renamed HealthInnovation.

To recruit firm members, the network orchestrator drew a map of the relevant regional firms and decided to visit them in person. She allocated 2-3 months to this phase, developed an interview guide, and visited 40 firm managers. The most important questions in the interview guide were: "Are you interested in innovation?" "Are you interested in cooperating with regional knowledge institutions?" "Are you interested in R\&D?" She further challenged the firms on their market situation and asked them to reflect upon whether their core technology could possibly be relevant in the rapidly growing healthcare market. During her 40 visits, the orchestrator 
succeeded in motivating 12 firms with relevant technology to cooperate in the refocused HealthInnovation network. Their core competence was largely on ICT and technology, few firms had any experience in cooperating with researchers and all but one had no previous experience within the health market. Hence, the network was refocused and several firms were recruited as network members. Still, at this point the companies had only a vague notion of what they had in common and what issues and projects they were to cooperate on.

To develop a common and deeply rooted vision and strategy, define common unique knowledge, common opportunities, strengthen the sense of connectedness, and develop joint projects, the orchestrator initiated a plan to organize four workshops in 2009 and 2010. She put a lot of effort into motivating the actors for participation in the workshops, as reflected in one of the participants' comment: "The orchestrator hassled me into participating today, and I am so glad that I am here." This resulted in participation from 12 firms, the university, the regional hospital enterprise, and the municipality. The same representatives from the firms participated in all the workshops, but the presence of representatives from the university, the hospital, and the municipality was more fluctuating, and new persons turning up at each workshop constituted a challenge. The workshops were organized as a foresight process, with team-work as the main ingredient. The orchestrator reorganized the teams prior to each workshop; therefore, different participants met each other and worked together each time. Each workshop lasted for 2 days, entailed an overnight stay at a retreat and had about 22 participants. The content and date of the workshops are outlined in Table 3.

The participants, the network orchestrator, and the foresight facilitator all emphasized the importance of the informal social interaction, such as dining and wining together in the evening. At a regional seminar presentation (VRI seminar) in November 2010, the network orchestrator described the process of the first workshop in the following manner:

I took 10 engineers, 10 nurses, some employees from the municipality and a dozen bottles of wine and locked them in a room until they had figured out something smart....

Without that workshop there would not have been enough goodwill to engage in Healthinnovation.

The first workshop ended with general consensus on "healthcare as an important marked for new technology in the near future," and with high hopes for considerable increase in this market due to demographic development and decrease in the

Table 3 Workshops during the foresight process

\begin{tabular}{ll}
\hline Date & Content \\
\hline $\begin{array}{l}\text { June 2009 } \\
\text { September 2009 }\end{array}$ & $\begin{array}{l}\text { Kick off_-"Future-workshop" } \\
\text { of commitments and priorities. Specification } \\
\text { November 2009 }\end{array}$ \\
$\begin{array}{l}\text { Market scenarios. Presentation of two member } \\
\text { businesses }\end{array}$ \\
February 2010 & Vision and goals \\
\hline
\end{tabular}


workforce. This represented new thoughts and a turn-around for the firms, who previously had not even considered the health sector as a potential marked. The participating organizations also came to realize that their core competence and areas of expertise were complementary and apt to jointly develop concepts, products, and organizational models aimed at forming a competitive edge in the healthcare market. Interest in, and acknowledgement of, interaction and cooperation as important factors for achieving success within the health care technology market increased among the actors during the subsequent workshops.

Although the workshops were facilitated by an external consultant, the orchestrator influenced the program, participated actively and acted as a visible leader with clear standpoints. She challenged the participants on important decisions about the present and the future, e.g., on funding an orchestrator and secretary after the end of the public funding period in 2012. To sum up: the orchestrator initiated the workshops, suggested to organize them as a foresight process, and performed clear and visible network leadership for the entire duration of the workshops. Through initiating the foresight process she orchestrated the construction of a strategy for the recovery of the former failing network.

\section{Results of Implementing the Strategy for Recovery}

In the autumn of 2010, 2 years after the health assessment process started, the network cooperation has yielded important results for the firms, the public sector, and the university. The results are visible above all in greater openness and transparency between the firms, also with respect to their technological platforms. The actors have defined common unique knowledge, common opportunities, common goals and strategies, and common innovation projects. Two new firms are established, one as a spin-off from another firm and one as a joint venture. Moreover, the Department of Health Science at the regional university has been mobilized and their attention is now turned towards cooperation with the industry. Traditionally, this department has had strong ties to the public sector and public hospitals, but rarely to private firms. As one firm representative expressed in a workshop in September 2010, "The University distinguishes itself by its willingness to make use of technology and demonstrates a desire to change." Practitioners from the firms are mobilized as lecturers for the nursing students. Traditionally, there has been little contact between the Department of Technology and the Department of Health Science, in academia in general and in this university in particular. However, the combination of two fields - healthcare and technology - in this network appears to have had a rub-off effect and has contributed to increased interaction within the regional university. This, in turn, has resulted in the initiation of a new project between the two departments to develop a new subject: health technology. This subject, the development of which is financed by the county administration, is envisaged to fit into a Master's program in nursing. Furthermore, a new project, funded by Innovation Norway and entitled Intelligent Healthcare Services has been launched.

The network made a practical turn as it started interacting with Drammen municipality, which is an urban municipality just south of Oslo with 63,000 inhabitants. The municipality initiated a project parallel to the development of the HealthInnovation network: The building of 16 senior citizen housing units with advanced technology- 
senior citizen housing for the future. This proved to be an idea that all the participants found very exciting. It was already a fully developed idea, which meant that there would be some funding available, and it seemed realistic and feasible. A lot of effort has since been made by the network orchestrator and the firms to define possible contributions from the firms in HeathInnovation. This was classified and funded as a "Private Public Partnership" (PPP) project and it received funding in October 2010. Actually the PPP project consists of nine PPP contracts, one with each of the eight participating firms and one "umbrella contract" linking them all together, legally and technically. This way of connecting PPP contracts is unique in Norway and represents an innovation in itself. In addition to the firms, both the university and Drammen municipality cooperate in this project. Their intention is, among other factors, to link research projects and $\mathrm{PhD}$ candidates to it. Finally, three applications are developed for a regional research fund. In the autumn of 2010 the participants have signed formal binding agreements in order to regulate rights and obligations. Thus, the network is not merely a loosely coupled network. Moreover, according to the orchestrator, "An insane trust-capital has now developed among the participants." The network cooperation has therefore yielded several important results, which are outlined in Table 4.

In a national foresight seminar in September 2010, the national manager of the Arena program expressed the following statement about the HealthInnovation project: "If this project had not had such a strong, clear and bold network orchestrator, it would not have worked."

Table 4 Results from the recovery process

\begin{tabular}{ll}
\hline Actor & Result \\
\hline The firms & Two new firms \\
Greater openness and transparency between the firms & Shared technological platform \\
& New market \\
Increased cooperation with firms & Increased cooperation between the Department of Health Science \\
and the Department of Technology \\
Guest lectures from the firms \\
A new Master's subject in Health Technology funded by the county \\
Building 16 senior citizens housing units with advanced technology \\
(no results pertaining solely to the hospital) \\
Increased connectivity and cooperation \\
Increased trust \\
Amo hefined common knowledge, opportunities, vision, goals, strategies, \\
and innovation projects \\
A new innovation project: Intelligent Health Care Services \\
Nine PPP contacts with public funding for about 450,000 Euro \\
Three research applications \\
Formal agreements to regulate rights and obligations
\end{tabular}




\section{Discussion}

When assessing the network's health, the orchestrator acknowledged that the network had several serious problems. She discovered that health and lighting was a relatively narrow domain, without a large regional — or national — market. The network developed here is a regional network that includes all the actors in the Triple Helix framework [11]: Firms, public sector (government) and university. Cooke [4] argues that in order to be innovative such networks need to have symmetric knowledge. To fulfill this, three criteria are required: (1) The quality of information among the actors needs to be safe and of current interest. (2) The university needs to be research-oriented, and (3) equilibrium in knowledge and innovation practice among the triple helix actors is required. The network faced problems with all these criteria, but especially with the third one; the university dominated the network and the two other actors, the industrial actors and the public sector, were more or less absent and uninterested in this domain. Furthermore, the cooperation on research issues between the two departments at the regional university was difficult to initiate, and the number of relevant projects was close to zero. When assessing the network's health through its contribution to the members, it was discovered that the network did not stimulate innovation activity by its members - mostly due to the lack of active firms, a passive public sector, and a very small market. The network did not create value for its members, was rather kept artificially alive by public funding and was in danger of succumbing.

The main results after the recovery are the creation of a common vision, an increased connectivity and trust, several new development and research projects, a new subject at the university, and two new firms. The network currently creates value and contributes to innovation for its members, by opening a new market (market innovation), by new ways of working utilizing R\&D in product development and by cooperating with new actors (organizational innovation), by promoting joint development of new products (organizational and product innovation), and entrepreneurship (new firms).

In the recovery process, all three of Dhanaraj and Pharkhe [6] processes were utilized: managing of knowledge mobility, innovation appropriability, and network stability. Knowledge mobility was managed by facilitating the foresight workshops, motivating the members to participate and share valuable knowledge, enhancing trust building processes, acquiring knowledge from the different actors, and deploying it in new contexts/markets using the core competence framework [16]. Innovation appropriability was deployed to stimulate the workshop participants to recognize and develop innovative ideas, e.g., advanced technology for senior citizen housing and a new university subject; moreover, it was managed by governing the ability to capture the profits in the PPP projects and developing formal agreements to regulate rights and obligations. Network stability was obtained by recruiting new firm members, developing common visions, and goals for the future, and calling the members to collaborate on several projects thus expanding the scope of the relationships.

It could be argued that network stability includes assessing the network health. We argue, however, that the two dimensions diverge in several important aspects. One aspect relates to the nature of the SME network. Since this kind of network typically lacks the hub firm which was so central in Dhanaraj and Pharke's framework, both the notion of stability and that of network health has a different 
meaning. Because SME networks lack hub firms, the kind of stability deduced from enhancing the hub firms' own reputation is unattainable for them. Meeting the threat of instability through "lengthening the shadow of the future" ([6]:664), or motivating the members to remain in the network with the prospect of future gains, does apply also to SME networks, albeit in a different manner, due to lack of the hub firm as a locomotive. In SME networks this will be a joint effort. Because a SME network lacks a hub firm, increasing the multiplexity by the hub firm undertaking additional joint projects with network members and thereby expanding the scope of their relationships, is inaccessible to it. Furthermore, the survival of a hub firm network is mostly dependent of the hub firm: if other members abandon the network, the hub firm can go elsewhere and recruit new suppliers and network members. "By its strategic choice of partners, a hub firm can significantly change network membership (size and diversity) and structure (density and autonomy). Through such recruitment and brokering activities, the hub firm can control its network position, maintaining its centrality and status" ([6]: 661). The survival of a SME network is dependent of sufficient contributions by the SMEs. If sufficient firms abandon a SME network, the network will die. We argue that orchestrating the network health will prevent this danger, and that network stability is about the networks fitness, while network health is about the network's life or death.

\section{Concluding Remarks}

This longitudinal case study of a network development process and how it was orchestrated has contributed to the development of a new framework for the orchestration of SME networks. It has, moreover, contributed to a new definition of network orchestration. The research question to be answered was: What are the processes of successfully orchestrating innovative SME networks? We maintain that in order to successfully orchestrate innovative SME networks, the orchestration process must consist of managing knowledge mobility, managing innovation appropriability, managing network stability, and managing network health. Managing network health includes evaluating the network's contribution to its members. If the evaluation reveals an unhealthy network with little vitality, the orchestrator's role includes the initiation of actions aimed at recovering the network. To apply the orchestration of SME networks, we argue that network stability in Dhanaraj and Pharkes' framework lacks the dimension of network health. As a conclusion, we maintain that the existing literature on network orchestration, to fit SME networks, lacks the process of "managing network health." A new framework is therefore developed in Table 5, building on the

Table 5 Framework for orchestrating SME networks
Processes of network orchestration

Managing knowledge mobility

Managing innovation appropriability

Managing network stability

Managing network health 
framework of Dhanaraj and Pharkhe [6]. By adding elements from the CoP theory it is more suitable for networks of interdependent SMEs without a dominant hub firm.

A single case study is a limited base for outlining a general theory, therefore further studies are needed. The aim of the present study, nonetheless, is that of increasing our understanding of the phenomenon and developing the existing theory. Because of the poor network health in 2008 and the dramatic recovery process with the following impressive and fast results, we argue that HealthInnovation is a suitable case for increased understanding and theory development. However, we also acknowledge that 2 years is a short time span and that it is premature to conclude on the further success of HealthInnovation. In the case description, we have emphasized the role of the orchestrator. The results of course depend also on the development of a community feeling among the network members. We argue, however, that the orchestrator has contributed significantly in developing this feeling. The findings and exploratory analysis need to be followed-up, and the framework needs further testing. Additional factors need further inspection, such as trust-since trust is essential for innovative collaboration [20]. We maintain that the four processes in Table 5 are important in orchestrating SME networks. We do not, however, claim that the four processes are totally adequate for orchestration of all processes in orchestrating such networks. There is a definite need for further studies on how innovative networks of SMEs are orchestrated and on how network participation creates value for its members.

Acknowledgments The research for this paper was aided by support from the Norwegian Research Council's VRI program (VRI means for regional R\&D and innovation). The authors are grateful for helpful comments from Bjørn Gustavsen, the anonymous reviewers, and the editors.

\section{References}

1. Batterink MH, Wubben EFM, Klerkx L, Omta SWF (2010) Orchestrating innovation networks: the case of innovation brokers in the agri-food sector. Enterpren Reg Dev 22(1):47-76

2. Brown JS, Duguid P (2000) Mysteries of the region: knowledge dynamics in Silicon Valley. In: Lee C-M (ed) The Silicon Valley edge a habitat for innovation and entrepreneurship: xxiii. Stanford University Press, Stanford, p 424

3. Brown JS, Duguid P (2001) Knowledge and organization: a social-practice perspective. Organ Sci $12(2)$

4. Cooke P (2007) Regional innovation systems, asymmetric knowledge and the legacies of learning. In: Rutten R, Boekema F (eds) The Learning region: foundations, state of the art, future. Edward Elgar, Cheltenham, pp 184-205

5. Czarniawska B (1998) A narrative approach to organization studies. Sage, Thousand Oaks

6. Dhanaraj C, Pharkhe A (2006) Orchestrating innovation networks. Acad Manage Rev 31(3):659-669

7. Duguid P (2008) The art of knowing. Social and tacit dimensions of knowledge and the limits of the community of practice. In: Amin A, Roberts J (eds) Community, economic creativity, and organization: XVII. Oxford University Press, Oxford, p 303

8. Duguid P (2008) Prologue: community of practice then and now. In: Amin A, Roberts J (eds) Community, economic creativity and organization. Oxford University Press, Oxford

9. Dyer JH, Nobeoka K (2000) Creating and managing a high-performance knowledge-sharing network: the Toyota case. Strat Manag J 21(3):345-367

10. Eisenhardt KM (1989) Building theories from case-study research. Acad Manage Rev 14(4):532-550

11. Etzkowitz H, Leydesdorff L (1997) Universities and the global knowledge economy: a triple helix of university-industry-government relations. Pinter, London 
12. Flyvbjerg B (1991) Rationalitet og magt. Akademisk Forlag, København

13. Freeman C (1991) Networks of innovators - a synthesis of research issues. Res Pol 20(5):499-514

14. Gausdal AH (2008) Developing regional communities of practice by network reflection: the case of the Norwegian electronics industry. Enterpren Reg Dev 20(3):209-235

15. Gausdal AH (2008) Hvordan skape innovative nettverk? MAGMA 11(5):53-63

16. Hamel G, Prahalad CK (1994) Competing for the future. Breakthrough strategies for seizing control of your industry and creating the markets of tomorrow. Harvard Business School Press, Boston

17. Hartley J (2004) Case study research. In: Cassell C, Symon G (eds) Qualitative methods in organizational research. A practical guide. Sage, London

18. Hoang H, Antoncic B (2003) Network-based research in entrepreneurship-a critical review. J Bus Venturing 18(2):165-187

19. Inkpen AC (1996) Creating knowledge through collaboration. Calif Manage Rev 39(1):123-140

20. Keeble D (2000) Collective learning processes in European high-technology milieux. In: Keeble D, Wilkinson F (eds) High-technology clusters, networking and collective learning in Europe. Ashgate, Aldershot, pp 199-229

21. Keeble D, Wilkinson F (1999) Collective learning and knowledge development in the evolution of regional clusters of high technology SMEs in Europe. Reg Stud 33(4):295-303

22. Maskell P, Eskelinen H, Hannibalsson I, Malmberg A, Vatne E (1998) Competitiveness, localised learning and regional development: specialisation and prosperity in small open economies. Routledge, London

23. Orton JD, Weick KE (1990) Loosely coupled systems: a reconceptualization. Acad Manage Rev 15 (2):203-223

24. Pittaway L, Robertson M, Munir K, Denyer D, Neely A (2004) Networking and innovation: a systematic review of the evinence. Int J Manag Rev 5-6(3-4):137-168

25. Reason P, Bradbury H (2001) Introduction: inquiry and participation in search of a world worthy of human aspiration. In: Reason P, Bradbury H (eds) Handbook of action research: participative inquiry and practice. Sage, London

26. Saxenian AL (1994) Regional advantage: culture and competition in Silicon Valley and Route 128. Harvard University Press, Cambridge

27. Siggelkow N (2007) Persuasion with case studies. Acad Manage J 50(1):20-24

28. Szulanski G (1996) Exploring internal stickiness: impediments to the transfer of best practice within the firm. Strat Manag J 17:27-43

29. Uzzi B (1997) Social structure and competition in interfirm networks: the paradox of embeddedness. Adm Sci Q 35-67(42)

30. Wenger EC (1998) Communities of practice: learning, meaning, and identity. Cambridge University Press, Cambridge

31. Wenger EC, McDermott R, Snyder WM (2002) Cultivating communities of practice: a guide to managing knowledge. Harvard Business School Press, Boston

32. Yin RK (1984) Case study research: design and methods. Sage, Beverly Hills 